\title{
GUIDELINES FOR SIMULATION PROJECT SUCCESS
}

\author{
Kenneth J. Musselman \\ Pritsker Corporation \\ P.O. Box 2413 \\ West Lafayette, Indiana 47906-0413, U.S.A.
}

\begin{abstract}
Project success comes with improving system performance. Sound project management methods help guarantee this success. The management guidelines provided in this paper aid in directing the simulation process, controlling model development and analysis, and improving customer relations.
\end{abstract}

\section{INTRODUCTION}

When system performance improvements result from carrying out a simulation project's recommendations, the feeling on the project team can be euphoric. Their sense of pride is self-evident.

Unfortunately, not all project teams experience this, for not all projects are successful. Some never finish. Others finish, but not with enough credence to persuade the customer to take any action. And still others fail to finish in time to make a difference.

While success cannot be guaranteed, conducting a simulation project according to certain guidelines can improve the team's chance of success. The guidelines presented here are straightforward, even commonplace, actions that have repeatedly proven their value.

Technical fundamentals are not emphasized. This is not to minimize their importance, for technical knowledge and competence are necessary conditions for success. Rather, the purpose is to emphasize the role practical management plays in every successful project.

\section{PROJECT STEPS AND GUIDELINES}

A simulation project is a process of interpretive, developmental, and analytical steps (Pritsker, Sigal, and Hammesfahr 1989, Banks and Carson 1984, Law and Kelton 1991). These steps, which are intrinsic to all simulation projects, generally include problem formulation, model conceptualization, data collection, model building, verification, validation, analysis, documentation, and implementation.
A functional definition is given below for each step in the simulation process (Pritsker 1986, Pritsker Corporation 1993). Following each definition, guidelines are presented. These guidelines affect the success of the project at this point in the process. Keep in mind, however, a particular guideline may need to be initiated well ahead of where it is placed here and could be engaged repeatedly.

\subsection{Problem Formulation}

Define the problem to be studied, including a written statement of the problem-solving objective.

\subsubsection{Work on the Right Problem}

Nothing is less productive than finding the right solution to the wrong problem. While this is usually not one's intention, it happens more frequently than it should. Often, this is due to misunderstood or poorly stated objectives.

For this reason, establishing sound objectives is critically important. Obscure objectives make it difficult to succeed. Construct objectives that are precise, reasonable, understandable, and action-oriented to convey a proper sense of direction and to distinguish between primary and subordinate issues. Then continue to focus on these objectives throughout the project.

Maxim

Fuzzy objectives lead to unclear successes.

\subsubsection{Listen to the Customer}

Good listening habits are essential for success. Learn to listen more and talk less. Give the customer a chance to change your way of thinking. Remember, the goal is to solve the customer's problem, not yours.

Work on suspending judgment until you better understand the system and the situation. Know who the 
customer is, what is being asked, and why. Concentrate on what is, as well as what is not, being said. Draw out the facts and encourage further clarification. Don't let vague answers or unfamiliar terminology curb your need to know.

$\mathrm{Be}$ as aware of your question selection as you are of your customer's answers. Learn to probe with pro-active questions. "What if we release it later? Earlier? Suppose we do it more often? Less often? How about eliminating it altogether?" Try compressing, adding, subtracting, multiplying, substituting, combining, and reversing your way through the system.

Also be more circumspect. Part of finding a solution involves understanding its implications. Continually sensitize yourself to the customer's needs, values, beliefs, and attitudes. Be on the alert for clues into how the customer views the problem and the project. Then couch your comments, reports, documents, and presentations accordingly.

Maxim
Don't look for a solution
without first listening to the problem.

\subsubsection{Communicate}

Poor communication is the single biggest reason projects fail. There is simply no substitute for good communication.

Start by reaching an understanding with the customer about the project. Settle on objectives, scope, assumptions, how the system functions, key questions to be addressed, model input, and model output. At this point, you want everyone to understand clearly the project team's collective knowledge and intent.

Next, orient the customer by establishing a project plan. Gain the customer's support by explaining how the project will proceed and what to expect. Emphasize the benefits associated with doing the project as planned and prepare the customer for potential problems. In short, give the customer a "road map" of the project. By knowing what is coming and why, the customer is in a better position to lend support. Without this knowledge, the customer may unintentionally work against you.

Finally, keep the customer informed. People like knowing where they are. Have plenty of "sign posts" along the way. Easily identifiable deliverables are excellent for this.

\section{Maxim}

Keep people informed, for the journey is more valuable than the solution.

\subsubsection{Predict the Solution}

In the beginning of a project, people often miss an excellent opportunity to properly set the stage. They are too eager to get started. As a result, they fail to do a simple, yet effective, exercise.

At project initiation, ask the customer to conduct a quick, even crude, analysis of the problem. This does several things for you. First, it gets the thought process started. The customer begins to concentrate on the problem more than the model. This can provide early insight into the problem. Caution is advisable, however. Preconceived ideas can restrict thinking. Don't let this happen. Keep creativity alive. You want this exercise to strengthen the thought process, not stop it.

Second, this starting solution provides a base for comparison. If the project's results turn out differently, you arouse interest. This leads to exploration into why these differences exist and, eventually, to an even deeper understanding of system behavior.

Finally, predicting the solution establishes where the customer's thinking was at the beginning of the project. Eventually, you want to show how the project advanced understanding. Without this beginning reference point, you have no way of doing this. Accordingly, the project's true value could be discounted.

$$
\text { Maxim }
$$

Only by knowing where you started can you judge how far you've come.

\subsection{Model Conceptualization}

\begin{abstract}
the system into a model described by the elements of the system, their characteristics, and their interactions, all according to the problem formulation.
\end{abstract}

\subsubsection{Direct the Model}

The best guide for formulating a simulation model is a well-defined set of objectives. These objectives establish the criteria against which all modeling decisions can and should be judged.

With these objectives as a basis, use a backward pass to reach the model specification stage. This is accomplished as follows. As shown in Figure 1, first generate a list of specific questions that support the project's objectives. These questions provide the direction needed to identify the most important areas in the system. Next, determine what output measures are necessary to answer these questions. Then by limiting the discussion to just these measures, begin to define and scope the model. This process helps ensure that the 
model is consistent with the project's objectives.

Formulating the model backwards as suggested above results in a leaner model. This provides several benefits: easier model verification, quicker initial results, and improved ability to adjust the model as necessary.

\section{Maxim}

Advance the model by formulating it backwards.

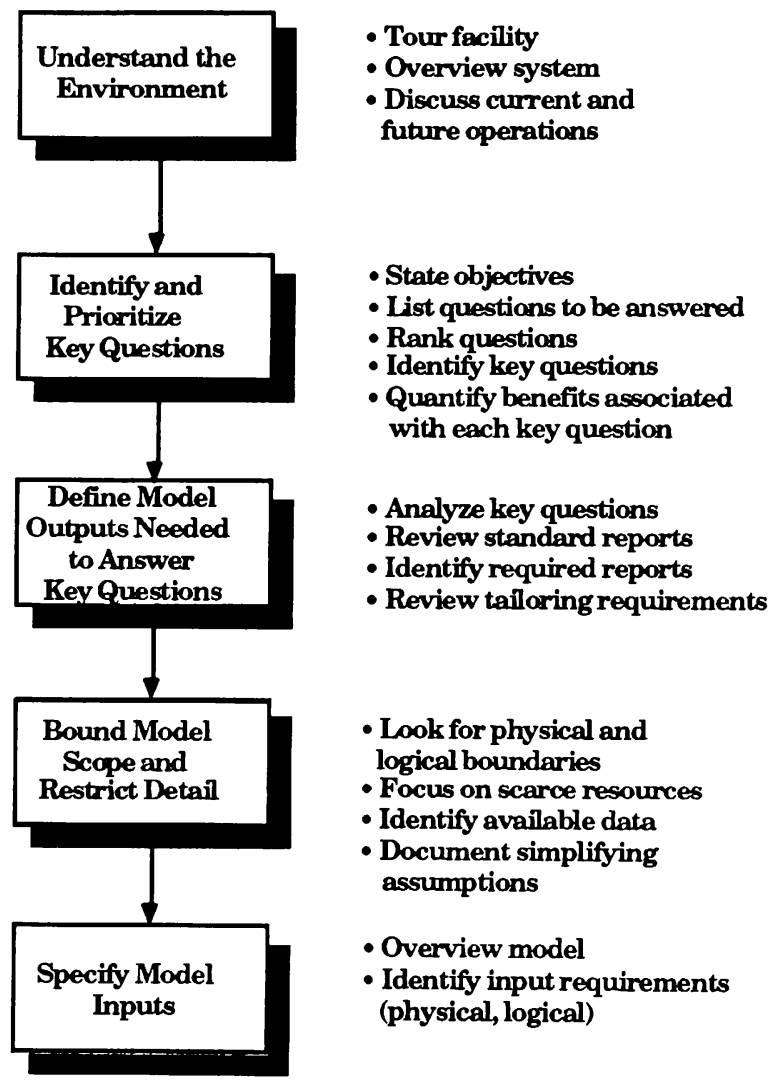

Figure 1: Model Formulation Procedure.

\subsubsection{Manage Expectations}

Successful projects require continuous management of the customer's expectations. It is important to have these expectations agree with the project's objectives. Otherwise, you can find yourself obligated to perform tasks only to satisfy an expectation, not an objective.

Start by setting the correct expectations upfront. Be enthusiastic, but be careful not to oversell. Make sure the customer understands what issues the model will and will not address. It is far better to discuss restrictions from the beginning than to state them for the first time when you present results.
Then continually manage the customer's expectations. Quickly throttle any unrealistic hopes or ideas. Don't let the customer assume you are delivering capability you cannot or do not intend to deliver. Work together to understand each other's viewpoint and come to a mutually acceptable resolution.

If you cannot reach agreement immediately, look for a way to work around the issue. You want to keep the project moving forward. If the issue is technical, consider using the model to explore options or to bound the problem to see if the issue really matters.

\section{Maxim}

It is easier to correct an expectation now than to change a belief later.

\subsection{Data Collection}

Identify, specify, and gather data to support the model.

\subsubsection{Question the Data}

Challenge all data you get for the model. Do a quick audit. Consider the source, what was collected, and how it was collected. Does the data make sense? Is it representative of the process? Is it at an appropriate level of detail? Is it within the scope of the project? Is it going to bias the results?

Strive to get all the data you need, but be open to compromising the model to better suit the data you can get. Then test the sensitivity of the model's outputs to the full range of input possibilities. If sensitivity exists, you now have a good reason to get the data you need.

\section{Maxim}

Don't take data for granted.

\subsubsection{Make Assumptions}

Data collection will inevitably be on the critical path. Don't be held captive by the information you lack. Be willing to make assumptions to keep the project moving forward. Take an educated guess at what you don't know. Then use the model to judge the sensitivity of this information. You may find it is of little consequence.

Making an assumption does not mean you must hold to it. Learn to revise your thinking and your assumptions throughout the project. Making unconfirmed assumptions are only a problem if you treat them as if they were fact. Finally, review your assumptions regularly and be sure to validate them before presenting results. 
Maxim

Be willing to make assumptions.

\subsection{Model Building}

Fit the conceptualized model to constructs available in a simulation language or system.

\subsubsection{Focus on the Problem}

Many simulation projects inappropriately concentrate on model building more than problem solving. Getting the model up and running becomes the overriding objective. Understanding the problem and deriving possible solutions become subordinate.

Consider, instead, spending more time modeling and experimenting, and less time building. Use the process of modeling to gain more insight into the problem and possible solutions. New ideas will come with the knowledge gained in modeling the process. You want to give the model a chance to contribute to the process of originating new ideas. Remember, building the model is not the main task at hand; implementing the right solution is.

\section{Maxim}

Focus on the problem more than the model.

\subsubsection{Start Simple}

Use the model to reduce the problem to your ability to solve it. If you build a complex model, you undermine your ability to understand the outputs produced by it and, ultimately, your ability to arrive at a solution. Therefore, initially avoid making the model too complex. Try, instead, to capture just the essence of the system. Then use your judgment skills to fill in the details.

Starting with a simple model also enables you to learn about the system in stages. By incrementally building the model both down and out, you better understand why things happen as they do and what the impact of each new stage is.

A simple model also helps you maintain modeling freedom. If you build a detailed model that now must be redone or significantly modified, you can find yourself arguing against change only because of the effort involved. It is best to maintain modeling freedom as long as possible.

\section{Maxim}

Add complexity; don't start with it.

\subsubsection{Curb Complexity}

Complexity can easily creep into a model. With perfect information available, a model's control logic, for example, can become so sophisticated it allows the model to out perform the actual system. This level of control in the model can conceal fundamental system design flaws. Seek to expose these flaws, not hide them.

Moreover, don't lose sight of what is reasonable to implement. Consider, for example, the situation where you are choosing the next best job to run on a machine. By including both waiting and incoming jobs in your search, system performance will likely improve. Yet, how intelligent should the model be? Can you implement the logic? Be ever mindful of what is practical. It can save precious modeling time and effort.

\section{Maxim}

Don't let the model become so sophisticated that it compensates for a bad design, or so complex that it goes beyond your ability to implement.

\subsection{Verification and Validation}

Establish the model executes as intended and the desired accuracy or correspondence exists between the model and the real system.

\subsubsection{Control Changes}

Change requests are inevitable. Therefore, expect them, plan for them, and, most of all, control them.

Begin by being smart from the start. Don't accept a small change just because the project is going well now. Stay true to the project's objectives and scope. Argue against a change that is not in line with the objectives or within scope. The true implications of a change usually become evident much later in the project, namely during verification, validation, acceptance testing, and implementation. Large costs and delays can easily result from even a minor change.

Agree to a change only if you must. When you do, be aware that you open yourself to more changes, with possibly even bigger consequences. Therefore, proceed with caution. Remember also that changes can delay deliverables that others are expecting. Consequently, be sure to communicate to all affected parties the implications of each change, especially the added time and costs.

Consider delaying changes by moving them to a later phase of the project. Get baseline results out first. Then look to incorporate the changes you deferred. This allows you to show progress under the original schedule and still satisfy the request. 
Include the customer in change request meetings. This gets the customer to think occasionally about the project's objectives and scope. It will also help the customer begin to appreciate, in advance, the reasonableness of these requests and their impact on the project.

Get all change requests in writing. A record of these requests and their judgments fosters good customer relations. If you have no record of what you agreed to or, more importantly, what you did not agree to, you are more likely to consent to the change.

Be especially mindful of changes in project personnel. If possible, argue against them. However, if you have no choice, immediately hold a project meeting. Review the team's accomplishments, what tasks remain, and who needs to be involved. Take the time necessary to properly transition all technical and administrative information. Make sure each team member knows what this means to him or her personally. Poorly executed transitions can quickly cause an otherwise secure project to fail. Don't miss this opportunity to get the project back on track. At the end of the project, it is too late to take the time to do it right.

$$
\begin{aligned}
& \text { Maxim } \\
& \text { Verbal agreements aren't worth } \\
& \text { the paper they're printed on. }
\end{aligned}
$$

\subsubsection{Be Mindful of the Customer's Perceptions}

Through experience you develop a way of doing things that works well for you. You know what is important to establish early and what can be left for later.

The customer, on the other hand, may have a different viewpoint. That which is unimportant to you may be very important to the customer. A small programming error, for example, if left unattended, can greatly undermine the customer's confidence in the simulation model and the project. Therefore, quickly correct any mistakes the customer perceives as a problem.

\section{Maxim}

Customer perceptions require attention.

\subsection{Analysis}

Analyze the simulation outputs to draw inferences and make recommendations for problem resolution.

\subsubsection{Sell Success}

Selling the value of a project continues throughout its life ... and beyond. It starts with the proposal and continues past implementation. Seize every opportunity to explain the value of what you are doing. Aggressively pursue these opportunities. Success will not come to you; you need to go after it.

Learn to accentuate the positive. You will have enough support in exposing the negative. Moreover, sell success, not underachievement. Compare your progress to where you were, not to where you are going. You will always be short of your objective until the end. Continue to remind everyone where the project started and how far it has come. At every opportunity, make known what you have accomplished.

Maxim

Report successes early and often.

\subsubsection{Question the Output}

Challenge the model's outputs. Can you explain them? Do they make intuitive sense? Can you defend them without getting into technical details?

Believe in yourself as much as the outputs. If the outputs are counter-intuitive, check your work. Something is wrong! Examine your assumptions. Reverify and revalidate the model. There must be a rational explanation.

In the end, compare the model's outputs with the crude estimate you asked the customer to perform at the beginning of the project. Are they different? If so, why? If not, examine why you did a simulation study so you can avoid doing "confirmation" projects in the future.

\section{Maxim}

If it doesn't make sense, check it out.

\subsubsection{Understand the Model's Limits}

At best, a model is less than reality. By its very nature, it is an abstraction of the system. This means a solution for the model is not necessarily a solution for the system. A degree of interpretation must accompany each analysis. Be careful not to stray beyond reasonable limits. Revisit the model's assumptions and inputs to help define what is reasonable.

Models do not replace individual thought. The customer, in the end, must rule on the worth of a particular solution. The model cannot do this. Its purpose is to support the thought process, not supplant it. 


\section{Maxim}

People decide; models don't.

\subsubsection{Know When to Stop}

You can always do more. For example, you can expand the model by extending it upstream and downstream, adding detail, improving the data, and reformatting the output. You can expand the analysis by testing the sensitivity of the results to boundary conditions, conducting a more rigorous statistical evaluation, examining other alternatives, and training the customer. The list is never-ending.

Prepare the customer for this eventuality. During the project, work with the customer to define a suitable stopping point. This is a judgment call, but one with which the customer must feel comfortable. You can help by instructing the customer on how to continue the process. This could involve teaching the customer how to change input, modify the model, interpret output, stay within scope, and decipher errors. The customer will deem the project far more successful if progress can continue following your departure.

\section{Maxim}

Ultimate truth is not affordable.

\subsubsection{Present a Choice}

The customer asks for a solution, but wants a choice. Therefore, present a range of possibilities to the customer. This gives the customer a sense of freedom and involvement, and a better understanding of why the best is best. Besides, with a choice, it is harder to find fault. It is much easier to dispute one solution, than a set of solutions.

\section{Maxim}

People don't resist their own discoveries.

\subsection{Documentation}

Supply supportive or evidential information for a specific purpose.

\subsubsection{Report Progress}

Progress reports provide an important, written history of a project. They give a chronology of work done and decisions made. This can prove to be invaluable as you endeavor to keep the project on course.
Reporting should occur at least monthly. In this way, people who are not directly involved in the project's dayto-day activities can stay involved. By knowing the project's status and plans, they still have an opportunity to further the project and your chance of success.

Regular reporting also surfaces misunderstandings early in the process, when problems can often be easily solved. You cannot afford to have them fester. Give them immediate visibility. Handling them without delay minimizes their impact.

Keeping a project log is also important. The log provides a comprehensive record of accomplishments, noteworthy problems, change requests, key decisions, ideas for follow-on work, and anything else of major or even minor importance. This can be indispensable when developing a historical record of the project.

\section{Maxim}

Document, Document, Document!

\subsubsection{Maintain Momentum}

A simulation project is a journey. Along the way, it is important to give the customer a reading of where you are. By showing progress and having the customer acknowledge this progress, enthusiasm for the project is kept high.

One means of doing this is by having frequent deliverables. These need not be major pieces of work. The best deliverables are easy to accomplish, hold value for the project, and are clearly identifiable. Examples include a model specification, prototype demonstrations, model delivery, animations, training, analyses, model documentation, progress reports, presentations, and a final report. Timing these deliverables judiciously over the project gives the customer a reliable measure of progress.

\section{Maxim}

It is better to work with many intermediate milestones than with one absolute deadline.

\subsection{Implementation}

\section{Fulfill the decisions resulting from the simulation.}

\subsubsection{Foster Teamwork}

A simulation project is more than building a model or managing a process; it is working with people. You must be able to work well with people if the project is to succeed, for success is in the minds of people. 
Working well together means taking full advantage of the team's collective talents. Learn to work as a unified body, with each member being aware of their role and importance to the general outcome of the project. By having the team search, discover, and grow together, you enrich the project and increase your chance of success.

\section{Maxim}

Focus on possibilities, not personalities.

\subsubsection{Involve Key Decision Makers}

Know who the key decision makers are and work to involve them in the project. Periodically meet with them to incorporate their ideas and allay their concerns. $\mathrm{Be}$ sure to involve the process owners from the beginning, even if they are not the key decision makers. In the middle of the project, you do not want either camp coming in with a different set of expectations. This can be both costly and demoralizing.

Watch for signs of the project not being a priority, such as data gathering delays, end user difficulties, upper management unavailability, decision postponements, deadline slippages, and apathetic or even hostile attitudes. When these signs appear, call on the key decision makers to reset the priorities.

\section{Maxim}

Pull in key decision makers to prevent being pushed out.

\subsubsection{Advocate Improvement}

If done right, a simulation project results in system improvements. These improvements are the result of change, such as a new operating policy, a different cell configuration, or a new job allocation scheme.

Whatever the change, expect resistance and take action to overcome it. Enlist management support; educate those affected as to the value of the change; sell the project team on the importance of being pro-active and enthusiastic about the change; and educate the customer as to the benefits associated with implementing the change. By involving everyone in the change process, you help mitigate any resistance.

Success in making a change is heavily dependent on the customer's confidence to take action. Giving the customer a sense of control over the project helps to instill this confidence. Learn, therefore, to guide the simulation process without usurping the customer's control. With loss of control, the customer becomes either angered or uninterested. In either case, the project falls into disfavor, and any action to implement the necessary changes is unlikely.

\section{Maxim}

Be a change-agent; have a bias for action.

\section{CONCLUSION}

Simulation projects demand strong technical and managerial skills. The guidelines presented here highlight the managerial skills needed in each step of the simulation process. They cover directing the process, controlling model development and analysis, and improving customer relations. By following these guidelines, the technical aspects of the project can continue with fewer distractions and disruptions. The result is improved project performance and increased likelihood of the project's recommendations being implemented.

\section{ACKNOWLEDGEMENTS}

This paper was originally published in the 1993 Winter Simulation Conference Proceedings. It has been revised for this proceedings.

\section{REFERENCES}

Banks, Jerry and John S. Carson II. 1984. DiscreteEvent System Simulation. Englewood Cliffs, New Jersey: Prentice-Hall.

Law, Averill M. and W. David Kelton. 1991. Simulation Modeling and Analysis, Second Edition. New York, New York: McGraw-Hill.

Musselman, Kenneth J. 1992. Conducting a Successful Simulation Project. Proceedings of the 1992 Winter Simulation Conference, ed. J. J. Swain, D. Goldsman, R. C. Crain and J. R. Wilson, 115-121. Arlington, Virginia.

Musselman, Kenneth J. 1993. Guidelines for Simulation Project Success. Proceedings of the 1993 Winter Simulation Conference, ed. G. W. Evans, M. Mollaghasemi, E. G. Russell and W. E. Biles, 58-64. Los Angeles, California.

Pritsker, A. Alan B. 1986. Introduction to Simulation and SLAM II, Third Edition. New York: John Wiley.

Pritsker, A. Alan B., C. Elliott Sigal, and R. D. Jack Hammesfahr. 1989. SLAM II Network Models for Decision Support. Englewood Cliffs, New Jersey: Prentice-Hall.

Pritsker Corporation. 1993. Simulation: A Decision Support Tool. West Lafayette, Indiana: Pritsker Corporation. 


\section{BIOGRAPHY}

KENNETH J. MUSSELMAN is Vice President of Services for Pritsker Corporation. For more than sixteen years, Dr. Musselman has been active in simulation consulting. $\mathrm{He}$ has conducted projects in a diversity of fields, including aerospace, automotive, communications, computers, consumer products, criminal justice, electronics, petroleum, and transportation. His specialty is in the design and scheduling of manufacturing systems. He served as General Chair for the 1989 Winter Simulation Conference. 